\title{
Suicide risk among prisoners in French Guiana: prevalence and predictive factors
}

\author{
Gülen Ayhan ${ }^{1 *}\left(\mathbb{D}\right.$, Romain Arnal ${ }^{2}$, Célia Basurko ${ }^{1}$, Vincent About ${ }^{3}$, Agathe Pastre $^{3}$, Eric Pinganaud ${ }^{2}$, \\ Dominique Sins ${ }^{2}$, Louis Jehel ${ }^{4,5}$, Bruno Falissard ${ }^{4}$ and Mathieu Nacher ${ }^{1,6}$
}

\begin{abstract}
Background: Suicide rates in prison are high and their risk factors are incompletely understood. The objective of the present study is to measure the risk of suicide and its predictors in the only prison of multicultural French Guiana.

Methods: All new prisoners arriving between September 2013 and December 2014 were included. The Mini International Neuropsychiatric Interview (MINI) was used and socio-demographic data was collected. In order to identify the predictors of suicide risk multivariate logistic regression was used.

Results: Of the 707 prisoners included 13.2\% had a suicidal risk, $14.0 \%$ of whom had a high risk, 15.1\% a moderate risk and $41.9 \%$ a low risk. Predictive factors were depression (OR 7.44, 95\% Cl: 3.50-15.87), dysthymia (OR 4.22, 95\% Cl: 1.34-13.36), panic disorder (OR 3.47, 95\% Cl: 1.33-8.99), general anxiety disorder (GAD) (OR 2.19, 95\% Cl: 1.13-4.22), men having been abused during childhood (OR 21.01, 95\%, Cl: 3.26-135.48), having been sentenced for sexual assault (OR 7.12, 95\% Cl: 1.98-25.99) and smoking (OR 2.93, 95\%, Cl 1.30-6.63).

Conclusion: The suicide risk was lower than in mainland France, possibly reflecting the differences in the social stigma attached to incarceration because of migrant populations and the importance and trivialization of drug trafficking among detainees. However, there were no differences between nationalities. The results reemphasize the importance of promptly identifying and treating psychiatric disorders, which were the main suicide risk factors.
\end{abstract}

Keywords: Suicide, Prisons, Child abuse, Mental disorders, South America

\section{Background}

According to the World Health Organisation (WHO), 800,000 persons in the general population commit suicide every year worldwide. The global standardized suicide rate is 11.4 for 100,000 habitants. WHO estimates that throughout the world every $3 \mathrm{~s}$, a suicide attempt occurs, and that every minute a suicide is committed [1]. Although the mechanisms of suicide are not completely understood, some risk factors have been identified, such as being a young male, belonging to an indigenous population, suffering from mental disorders or alcohol and/or substance abuse, having a previous history of suicide attempt and being in custody [2].

\footnotetext{
* Correspondence: guelen.ayhan@gmail.com

'Inserm CIC 1424, Centre d'Investigation Clinique Antilles Guyane, Centre Hospitalier de Cayenne, Avenue des Flamboyants, BP 6006, 97306 Cayenne CEDEX, France

Full list of author information is available at the end of the article
}

Prisoners are a particularly vulnerable group with a nine fold increase of suicidal risk and a two-fold increase of suicide rate when compared to the general population [1]. This makes suicide the leading cause of death in inmates and a public health problem [1,3]. Suicide in prison is not only a health concern because of its mortality but also because witnessing it has been identified as the most striking event during imprisonment [4].

Until today, there have been relatively few studies investigating suicide in prison. A British study revealed that the standardised mortality ratio for suicide was 5.1 (95\% CI, 4.8-5.3) in English and Welsh prisons in reference to the general population [5]. France has the highest suicide rate among 15 European countries, with an increasing rate in the last 50 years increasing from 4/10000 in the $1960^{\mathrm{s}}$ to $19 / 10000$ in 2008 , with a peak in 1996 of 26/10000. French inmates commit suicide 6 times more often than men in the general population [6]. Comparison 
of suicide rates worldwide seems to be complicated because of the differences of correctional conditions and inclusion criteria for suicides (whether committed after release, died in the hospital or in prison) [6].

Until today, there has been no significant correlation between overpopulation in prisons and the suicide rate, on the contrary, being alone in a cell is considered as a risk factor for suicide [7, 8]. In France suicide in prison occurs mainly at the beginning of incarceration, 25\% during the first 2 months and $50 \%$ in the first 6 months [9]. This is often explained by the incarceration shock which is related to the difficulty of adapting to prison, the deprivation of liberty, ostracism and the humiliation due to the disclosure of a committed crime in front of family and society $[10,11]$. Mental illness seems to be an important factor in prison suicidality [12]. In Spain, suicidality in prison was associated with certain psychiatric diagnoses, including affective disorder, substance dependence disorders, personality disorders, anxiety disorder and a family psychiatric history [13]. A European supranational study identified sexual offenders, offenders charged with violent crimes and prisoners sentenced for short- and longterm imprisonment to be at an higher suicide risk [14].

In a multinational review, no correlation was observed between the general suicide rate in the population and suicide in correctional circumstances, thus highlighting the entity of suicide in prison and the need for further investigation [6].

Upon request of the French Government, a nationwide survey of the prevalence of psychiatric illnesses in prisons in France and in Martinique (French West Indies) was conducted in 2004. Among 799 inmates, 40.3\% of those in France and 26\% of those in Martinique had a suicide risk [4]. The identification of predictive factors for suicide risk was not aim of that study.

French Guiana is a French overseas territory in South America between Northern Brazil and Suriname. Being a European country with access to a structured social system and economic advantages, it has a large immigrant population. Its population is very heterogeneous in terms of socio economic categories and cultures. The Guianese population is composed of Creoles, Maroons, Surinamese, Brazilians, Guyanese, Chinese, Hmong people and French from continental France. This diversified composition permits the investigation of different ethnic groups in one territory. The correctional centre in French Guiana is the only prison in this region. It has a capacity of 650 inmates. In 2011-2015, there were five suicides (annual average 15.3/10000) whereas in continental France 113 suicides for 65,000 inmates (17.4/10000) occurred.

Suicidality in general has never been investigated in French Guiana. PubMed research gave no relevant result but just one case report of toxic plant ingestion in a suicide attempt [15].
The objective of this study was thus to evaluate the prevalence of suicidal risk and its predictive factors in the correctional population of French Guiana. Studies have been conducted in metropolitan France and in Martinique, but this was the first study in this particular context of French Guiana.

\section{Methods}

In this cross-sectional study we included all consenting new adult prisoners incarcerated between 18/09/2013 and 31/12/2014 at the penitentiary centre of French Guiana, situated in Rémire-Montjoly, $10 \mathrm{~km}$ from the capital Cayenne. Inmates that were assigned a legal guardian were excluded. This decision was based on the fact that the required presence of the legal guardian would have been logistically very difficult given the restricted access to the mental health ward.

In the usual incarceration procedure, after passing administrational registration, all new arrivals are seen for physical examination by a doctor of the "Unité de consultation et de soins ambulatoires (UCSA) ", the ambulatory care unit of the prison and then by a psychiatrist or psychiatric nurse in the "Unite fonctionnelle de psychiatrie intra-carcérale (UFPI)", the psychiatric ward. In addition to this normal admission process and for the purpose of our study we added the Mini International Neuropsychiatric Interview (MINI). The MINI is a short diagnostic structured interview (DSI) developed in France and the United States to explore 17 disorders according to the Diagnostic and Statistical Manual (DSM)-V diagnostic criteria. Its validity and reliability has been confirmed in several studies [16-21]. Its applicability has also been validated in different studies [22-24]. The MINI has been translated and validated in 46 languages [20]. It is structured to allow use by non-specialized interviewers for the research of current disorders and is today one of the most used psychiatric diagnostic tools [25]. For each pathology, one or two screening questions rule out the diagnosis when answered negatively. Hence, the MINI is adapted for epidemiological studies with a need for a short but robust tool. The estimated time for passing the interview is $15 \mathrm{~min}$ [19]. The questions which evaluate the suicide risk (Suffer any accident? Plan or intend to hurt yourself in that accident either passively or actively? Did you intend to die as a result of this accident? Think that you would be better off dead or wish you were dead? Want to harm yourself or to hurt or to injure yourself? Think about suicide? Have a suicide plan? Take any active steps to prepare to injure yourself or to prepare for a suicide attempt in which you expected or intended to die? Deliberately injure yourself without intending to kill yourself? Attempt 
suicide? Did you ever make a suicide attempt?) and define its severity are presented in Table 1 [19]. The authors of the MINI defined three levels of suicide risk (low, medium or high risk). The MINI suicide risk scale has been prospectively validated in Sweden showing its potential to identify those at risk of committing suicide [26].

The MINI has been translated and validated for the main languages spoken in French Guiana: French, English, Portuguese, Dutch and Spanish. All psychiatrists and nurses performing the MINI were trained in order to use the questionnaire correctly. We included sociodemographic questions (age, birth place, residence, languages, presence of a translator, family status, children, siblings, position among siblings, professional situation), history of detention (reason for detention, previous imprisonment) and psychiatric history. A training period preceded our study in order to test the feasibility of the MINI and to familiarize the research staff with the protocol. Proficiency was verified before starting the study.

\section{Statistical analysis}

For statistical analysis we used Stata13 (College Station, Texas, USA). After descriptive analysis of qualitative and quantitative variables, we performed bivariate analysis in

Table 1 Questions of the MINI defining the suicide risk and its severity

\begin{tabular}{|c|c|c|c|}
\hline \multicolumn{4}{|l|}{ In the past month did you: } \\
\hline Item & Question & Answer & Points \\
\hline C1 & Suffer any accident? & NO YES & 0 \\
\hline \multicolumn{4}{|l|}{ IF NO TO C1, SKIP TO C2; IF YES, ASK C1a;: } \\
\hline Cla & $\begin{array}{l}\text { Plan or intend to hurt yourself in that accident } \\
\text { either passively or actively? }\end{array}$ & NO YES & 0 \\
\hline \multicolumn{4}{|l|}{ IF NO TO C1a, SKIP TO C2: IF YES, ASK C1b,: } \\
\hline $\mathrm{C} 1 \mathrm{~b}$ & Did you intend to die as a result of this accident? & NO YES & 0 \\
\hline $\mathrm{C} 2$ & $\begin{array}{l}\text { Think that you would be better off dead or wish } \\
\text { you were dead? }\end{array}$ & NO YES & 1 \\
\hline C3 & $\begin{array}{l}\text { Want to harm yourself or to hurt or to injure } \\
\text { yourself? }\end{array}$ & NO YES & 2 \\
\hline C4 & Think about suicide? & NO YES & 6 \\
\hline \multicolumn{4}{|c|}{ IF YES, ASK ABOUT THE INTENSITY AND FREQUENCY OF THE SUICIDAL IDEATION: } \\
\hline \multicolumn{4}{|l|}{ Frequency: Occasionally, Often, Very often } \\
\hline \multicolumn{4}{|l|}{ Intensity: Mild, Moderate, Severe } \\
\hline $\begin{array}{l}\text { Can you control these impulses and state } \\
\text { that you will not act on them while in this } \\
\text { program? Only score } 8 \text { points if response is NO. }\end{array}$ & & NO YES & 8 \\
\hline C5 & Have a suicide plan? & NO YES & 8 \\
\hline C6 & $\begin{array}{l}\text { Take any active steps to prepare to injure yourself } \\
\text { or to prepare for a suicide attempt in which you } \\
\text { expected or intended to die? }\end{array}$ & NO YES & 9 \\
\hline $\mathrm{C7}$ & $\begin{array}{l}\text { Deliberately injure yourself without intending to } \\
\text { kill yourself? }\end{array}$ & NO YES & 4 \\
\hline $\mathrm{C} 8$ & $\begin{array}{l}\text { Attempt suicide? } \\
\text { Hoped to be rescued/survive } \\
\text { Expected/intended to die }\end{array}$ & NO YES & 10 \\
\hline \multicolumn{4}{|l|}{ In your lifetime: } \\
\hline C9 & Did you ever make a suicide attempt? & NO YES & 4 \\
\hline $\begin{array}{l}\text { IS AT LEAST } 1 \text { OF THE ABOVE (EXCEPT C1) CODED YES? } \\
\text { IF YES, ADD THE TOTAL NUMBER OF POINTS FOR THE } \\
\text { ANSWERS (C1-C9) CHECKED 'YES' AND SPECIFY THE } \\
\text { LEVEL OF SUICIDE RISK AS } \\
\text { INDICATED IN THE DIAGNOSTIC BOX: }\end{array}$ & $\begin{array}{l}\text { NO } \\
\text { SUICIDE RISK CURRENT } \\
1-8 \text { points } \\
9-16 \text { points } \\
>17 \text { points }\end{array}$ & $\begin{array}{l}\text { Low } \\
\text { Moderate } \\
\text { High }\end{array}$ & \\
\hline
\end{tabular}


order to identify significant variables for suicide risk among inmates. Variables with $p<0.20$ were included in the multivariate model for logistic regression and backward stepwise elimination was performed in order to identify independent risk factors for suicide risk. Collinearity was ruled out by using the collin package (STATA, College Station, Texas) and verifying that variance inflation factors were $<4$. The Hosmer-Lemeshow goodness-of-fit test was used for the final model.

\section{Results}

Between September 18th 2013 and December 31st 2014, 785 new prisoners were registered in the correctional facility in French Guiana. The survey participation rate was $90 \%$ (707/785). The majority were males 647/707 (91.5\%) and the mean age was 30 years with a median of 27 years (18-71 years). Detainees were mostly born in French Guiana (47.8\%), followed by Surinam (15.1\%), Guyana (14.3\%) and Brazil (10.6\%). The remaining inmates were mainly born in Haiti, Martinique, Guadeloupe, and continental France. 54.4\% of the prisoners spoke French, 13.6\% English and 12.3\% Nenge Tongo, the language of the Maroons.

The MINI revealed that $14.3 \%(101 / 707)$ of the inmates suffered from depression, 5.4\% (38/707) had dysthymia, and $13.2 \%$ (93/707) had a suicidal risk, of which $14.0 \%(13 / 93)$ had a high risk, 15.1\% (14/93) a moderate risk and $41.9 \%$ (39/93) a low risk of suicide. For 27 of those detainees the level could not be estimated for unknown reasons. Furthermore the MINI identified a maniac disorder in $3.7 \%(26 / 707)$ cases, a panic disorder in 6.8\% (48/707), agoraphobia in $10.8 \%$ (76/707), social anxiety disorder (SAD) in $8.9 \%$ (63/707), obsessive compulsive disorder (OCD) in 2.1\% (15/707), post-traumatic stress disorder (PTSD) in 15.1\% (107/707), alcohol dependence in $17.5 \%$ (124/707), drug dependence in $33.2 \%$ (235/707), psychotic disorder in $7.2 \%$ (51/707), anorexia in $0.7 \%$ (5/707), bulimia in $0.4 \%$ (3/707), general anxiety disorder (GAD) in $25.7 \%(182 / 707)$ and antisocial personality disorder in $34.7 \%$ (245/707) cases. Among the inmates having a suicidal risk, the majority were men (87\%), the mean age was 29 years, $74 \%$ were living in an urban area, $81 \%$ spoke French during the interview, 52\% declared irregular odd jobs and $58 \%$ had previously been incarcerated (Table 2). Figure 1 describes for the motives of incarceration of the inmates with a suicide risk in our study population. Theft, robbery and drug trafficking were the main offenses. In the bivariate analysis, several past psychiatric conditions were significantly associated with suicide risk, depression having the highest Odds Ratio (OR 7.44; 95\% CI 3.50-15.84). Childhood abuse (OR 20.37. 95\% CI 5.27-78.77), especially for men (OR 26.74; 95\% CI 5.44-131.52), was strongly associated with suicide risk. Other variables such as smoking and drug consumption were independently associated with suicide risk (Table 2). After multivariate analysis, having been sentenced for sexual abuse, smoking, being male, childhood abuse, depression, dysthymia, panic disorder and GAD remained significantly associated with the risk of suicide. After ruling analysis with the Stata collin package variance inflation factors ranged between 1.0 and 1.91, therefore there was no collinearity problem.

\section{Comparison with other studies}

Suicide risk in prison in metropolitan France has also been assessed using the MINI. In mainland France $40.3 \%(322 / 799)$ of male prisoners had a suicide risk, in Martinique the risk was estimated to be 26\% (26/100). Among female prisoners in metropolitan France 61\% (61/99) had a suicide risk.

\section{Discussion}

The present study revealed that $13.2 \%$ of the inmates had a suicidal risk, $14 \%$ of which had a high risk. Risk factors included being sentenced for sexual abuse, being male, smoking, childhood abuse and psychiatric disorders such as depression, dysthymia, panic disorder and GAD. Compared to mainland France and Martinique, the prevalence was lower in French Guiana (Tables 3 and 4). It is not clear why the risk for suicide was lower. Perhaps, the high proportion of foreign detainees leads to an incarcerated population that often does not have strong community ties in French Guiana and thus is less subjected to social stigma. The frequency of drug trafficking in this transit region also presumably trivializes it and makes it less stigmatizing than in France. However, it is noteworthy that whereas the risk of suicide was relatively low, the actual average suicide rate was not significantly different than in mainland France [27]. In our study population, we found similar risk factors to those identified by the WHO and in previous studies [28]. After a Pubmed search for suicidality in prisons, we found just one study conducted in a Colombian prison [29] with $14.9 \%$ of the inmates with a high suicide risk, with the highest rates among single inmates under the age of 30, those who previously attempted suicide and suffering from domestic violence. In England and France the study of predictors showed that psychiatric illnesses were associated with the risk of suicide, being primordial because of the high prevalence of mental disorders among detainees $[23,30]$. The amplification of suicidality by psychiatric comorbidity in mood-disordered patients in general populations has been proven in several studies [31]. French Guianese prisoners with major depressive episodes had a high suicide risk, 
Table 2 Predictive factors of suicidal risk among detainees in the correctional centre of French Guiana, Cayenne 2013-2014

\begin{tabular}{|c|c|c|c|c|c|c|c|c|}
\hline \multirow{2}{*}{ Variables } & & \multicolumn{3}{|c|}{ Suicidal risk } & \multicolumn{2}{|l|}{ Crude OR } & \multicolumn{2}{|l|}{ Adjusted OR } \\
\hline & & Yes $n(\%)$ & No $n(\%)$ & $p$-value & OR $(95 \% \mathrm{Cl})$ & $p$-value & OR $(95 \% \mathrm{Cl})$ & $p$-value \\
\hline \multicolumn{9}{|l|}{ Gender } \\
\hline & female $(n=60)$ & $12(0.20)$ & $48(0.80)$ & 0.101 & $1.75(0.89-3.43)$ & 0.105 & $2.40(0.85-6.77)$ & 0.097 \\
\hline & male $(n=647)$ & $81(0.13)$ & $566(0.87)$ & & & & & \\
\hline Age & $(n=707)$ & 29 & 30 & 0.449 & $0.99(0.97-1.01)$ & 0.448 & $0.98(0.94-1.01)$ & 0.187 \\
\hline Number of children & $(n=704)$ & 2.2 & 2.0 & 0.466 & $1.03(0.95-1.12)$ & 0.466 & & \\
\hline Number of siblings & $(n=668)$ & 5.5 & 5.3 & 0.633 & $1.01(0.96-1.08)$ & 0.633 & & \\
\hline Position among siblings & $(n=n=288)$ & 2.6 & 2.9 & 0.483 & $0.94(0.78-5.13)$ & 0.483 & & \\
\hline Number of incarcerations & $(n=335)$ & 2.4 & 2.1 & 0.391 & $1.05(0.94-1.18)$ & 0.395 & & \\
\hline \multicolumn{9}{|l|}{ Domiciliation } \\
\hline & Town $(n=423)$ & $68(0.74)$ & $355(0.59)$ & $0.039^{*}$ & $2.51(1.17-5.40)$ & $0.018^{*}$ & $1.52(0.52-4.40)$ & 0.442 \\
\hline & Village $(n=23)$ & $2(0.02)$ & $21(0.03)$ & & $1.25(0.25-6.30)$ & 0.787 & $1.01(0.11-8.96)$ & 0.990 \\
\hline & Border town $(n=139)$ & $14(0.15)$ & $125(0.21)$ & & $1.47(0.59-3.64)$ & 0.405 & $0.76(0.22-2.63)$ & 0.662 \\
\hline & other $(n=113)$ & $8(0.09)$ & $105(0.17)$ & & & & 1 & \\
\hline
\end{tabular}

First language other than French

$\begin{array}{llllll}\text { yes }(n=292) & 41(0.44) & 251(0.41) & 0.575 & 1.13(0.73-1.76) & 0.575 \\ \text { no }(n=413) & 52(0.56) & 361(0.59) & & & \end{array}$

Second language other than French

$\begin{array}{llllll}\text { yes }(n=207) & 29(0.47) & 178(0.46) & 0.951 & 1.02(0.59-1.74) & 0.951 \\ \text { no }(n=239) & 33(0.53) & 206(0.54) & & & \end{array}$

Third language other than French

$\begin{array}{llllll}\text { yes }(n=146) & 26(0.84) & 120(0.67) & 0.055 & 2.60(0.95-7.11) & 0.063 \\ \text { no }(n=65) & 5(0.16) & 60(0.33) & & & \end{array}$

Forth language other than French

$\begin{array}{llllll}\text { yes }(n=49) & 11(0.92) & 38(0.70) & 0.127 & 4.63(0.55-38.93) & 0.158 \\ \text { no }(n=17) & 16(0.30) & 1(0.08) & & & \end{array}$

Language spoken during interview

$\begin{array}{llllll}\text { French }(n=563) & 74(0.81) & 489(0.80) & 0.070 & 1.00 & \\ \text { Brazilian }(n=37) & 2(0.02) & 35(0.06) & 0.38(0.89-1.60) & 0.187 \\ \text { Spanish }(n=6) & 2(0.02) & 4(0.01) & 3.30(0.59-18.36) & 0.172 \\ \text { English }(n=52) & 9(0.10) & 43(0.07) & 1.38(0.65-2.95) & 0.402 \\ \text { Nenge Tongo }(n=36) & 2(0.02) & 34(0.06) & 0.39(0.09-1.65) & 0.201 \\ \text { Dutch }(n=5) & 2(0.02) & 3(0.004) & 4.41(0.72-26.80) & 0.108\end{array}$

Employed

$\begin{array}{llllll}\text { yes }(n=289) & 46(0.52) & 243(0.43) & 0.110 & 1.44(0.92-2.26) & 0.111 \\ \text { no }(n=362) & 42(0.48) & 320(0.57) & & & \end{array}$

Previous incarceration

$\begin{array}{llllllll}\text { yes }(n=344) & 54(0.58) & 290(0.47) & 0.051 & 1.55(1.00-2.41) & 0.053 & 1.04(0.51-2.10) & 0.918 \\ \text { no }(=363) & 39(0.42) & 324(0.53) & & & & \end{array}$


Table 2 Predictive factors of suicidal risk among detainees in the correctional centre of French Guiana, Cayenne 2013-2014 (Continued)

Sentenced drug trafficking

$$
\text { yes }(n=243)
$$

no $(=458)$

Sentenced for sexual assault

$$
\text { yes }(n=32)
$$$$
\text { no }(n=675)
$$

Smoking

$$
\begin{aligned}
& \operatorname{yes}(n=383) \\
& \text { no }(=271)
\end{aligned}
$$

Drug consumption

$$
\begin{aligned}
& \text { yes }(n=344) \\
& \text { no }(n=331)
\end{aligned}
$$

Cannabis consumption

$$
\begin{aligned}
& \text { yes }(n=309) \\
& \text { no }(=398)
\end{aligned}
$$

$$
\begin{array}{ll}
53(0.57) & 256(0.42) \\
40(0.43) & 358(0.58)
\end{array}
$$

Abused in childhood

$$
\begin{aligned}
& \text { yes }(n=11) \\
& \text { no }(n=553)
\end{aligned}
$$$$
8(0.11) \quad 3(0.01)
$$$$
64(0.89) \quad 489(0.99)
$$

Interaction gender/abuse in childhood

$$
\begin{array}{lll}
\text { abused female }(n=2) & 1(0.01) & 1(0.002) \\
\begin{array}{l}
\text { abused male }(n=9) \\
\text { never abused female/ }
\end{array} & 7(0.10) & 2(0.009) \\
\begin{array}{l}
\text { male }(n=553) \\
\text { (0.004) }
\end{array} & 489(0.99)
\end{array}
$$

Depression

$$
\text { yes }(n=101)
$$$$
\text { no }(n=606)
$$

Dysthymia

$$
\text { yes }(n=38)
$$$$
\text { no }(n=669)
$$

Manic

$$
\text { yes }(n=26)
$$$$
\text { no }(n=681)
$$

Panic disorder

$$
\text { yes }(n=48)
$$$$
\text { no }(n=659)
$$

Agoraphobia

$$
\text { yes }(n=76)
$$$$
\text { no }(n=631)
$$

SAD

$$
\text { yes }(n=63)
$$$$
\text { no }(n=644)
$$$$
45(0.46)
$$

$56(0.55)$

$0.000^{* * *} \quad 9.34(5.72-15.26)$

$558(0.92)$

$$
19(0.50)
$$

$19(0.50)$

$74(0.11)$

$595(0.89)$

$$
8(0.31)
$$$$
18(0.69)
$$

$85(0.12)$

$596(0.88)$

$17(0.35)$

$31(0.65)$

$76(0.12)$

$583(0.88)$$$
17(0.22)
$$

$76(0.12) \quad 555(0.88)$

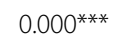


Table 2 Predictive factors of suicidal risk among detainees in the correctional centre of French Guiana, Cayenne 2013-2014 (Continued)

\begin{tabular}{|c|c|c|c|c|c|c|c|c|}
\hline \multicolumn{9}{|l|}{ OCD } \\
\hline & yes $(n=15)$ & $6(0.40)$ & $9(0.60)$ & $0.008^{* *}$ & $4.64(1.61-13.34)$ & $0.004^{* *}$ & $2.08(0.38-11.35)$ & 0.397 \\
\hline & no $(n=692)$ & $87(0.13)$ & $605(0.87)$ & & & & 1 & \\
\hline \multicolumn{9}{|l|}{ PTSD } \\
\hline & yes $(n=107)$ & $34(0.37)$ & $73(0.12)$ & $0.000^{* * *}$ & $4.27(2.62-6.95)$ & $0.000^{* * *}$ & $2.00(0.94-4.26)$ & 0.073 \\
\hline & no $(n=600)$ & $59(0.63)$ & $541(0.88)$ & & & & 1 & \\
\hline \multicolumn{9}{|c|}{ Alcohol dependence } \\
\hline & yes $(n=124)$ & $18(0.19)$ & $106(0.17)$ & 0.621 & $1.15(0.66-2.00)$ & 0.621 & & \\
\hline & no $(n=583)$ & $75(0.81)$ & $508(0.83)$ & & & & & \\
\hline \multicolumn{9}{|c|}{ Drug dependence } \\
\hline & yes $(n=235)$ & $49(0.53)$ & $186(0.30)$ & $0.000^{* * *}$ & $2.56(1.65-3.99)$ & $0.000^{* * *}$ & $1.44(0.60-3.45)$ & 0.418 \\
\hline & no $(n=472)$ & $44(0.47)$ & $428(0.70)$ & & & & 1 & \\
\hline \multicolumn{9}{|c|}{ Psychosis } \\
\hline & yes $(n=51)$ & $17(0.18)$ & $34(0.06)$ & $0.000^{* * *}$ & $3.82(2.03-7.16)$ & $0.000^{* * *}$ & $1.12(0.36-3.42)$ & 0.847 \\
\hline & no $(n=656)$ & $76(0.82)$ & $580(0.94)$ & & & & & \\
\hline \multicolumn{9}{|c|}{ Anorexia nervosa } \\
\hline & yes $(n=5)$ & $2(0.02)$ & $3(0.005)$ & 0.131 & $4.48(0.74-27.15)$ & 0.103 & & \\
\hline & no $(n=702)$ & $91(0.98)$ & $611(0.995)$ & & & & & \\
\hline \multicolumn{9}{|c|}{ Bulimia nervosa } \\
\hline & yes $(n=3)$ & $1(0.01)$ & $2(0.003)$ & 0.300 & $3.33(0.30-37.05)$ & 0.328 & & \\
\hline & no $(n=704)$ & $92(0.99)$ & $612(0.997)$ & & & & & \\
\hline \multicolumn{9}{|l|}{ GAD } \\
\hline & yes $(n=182)$ & $47(0.51)$ & $135(0.22)$ & $0.000^{* * *}$ & $3.63(2.31-5.68)$ & $0.000^{* * *}$ & $2.19(1.13-4.22)$ & $0.020^{*}$ \\
\hline & no $(n=525)$ & $46(0.49)$ & $479(0.78)$ & & & & & \\
\hline \multicolumn{9}{|c|}{$\begin{array}{l}\text { Antisocial personality } \\
\text { disorder }\end{array}$} \\
\hline & yes $(n=245)$ & $45(0.48)$ & $200(0.33)$ & $0.003^{* *}$ & $1.94(1.25-3.01)$ & $0.003^{* *}$ & $0.76(0.37-1.53)$ & 0.437 \\
\hline & no $(n=462)$ & $48(0.52)$ & $414(0.67)$ & & & & & \\
\hline
\end{tabular}

SAD Social Anxiety Disorder, OCD Obsessive-compulsive disorder, PTSD Posttraumatic stress disorder, GAD General anxiety disorder, OR Odds Ratio, $\mathrm{Cl}$ Confidence Interval-

${ }^{*} p<0.05,{ }^{* *} p<0.01,{ }^{* * *} p<0.001$

thus highlighting the need to identify them early given the temporal dynamics of the risk of suicide during incarceration [32]. Generalized anxiety is important to identify because it is a precursor in a number of actual suicides [33]. Little is known about the relationship between panic disorders and suicide in general and even less is known in the context of prison. Even if it is the subject of a long and controversial debate [31, 34], the impact of panic disorder on the severity of depression and the increased likelihood of suicide have been shown in the general population $[35,36]$. We found a similar association with a two-fold increase in suicide risk for subjects. As described elsewhere, the incarceration motive was associated with differences in suicidal risk [37, 38]. In mainland France, actual suicide was associated with sentences for harm to individuals, such as violence or homicide, and sexual assault [37]. In our study, having been sentenced for sexual assault or rape remained significantly associated with suicide risk with an OR of 5.98 in the final model. Although it was no longer significant in the multivariate analysis, those sentenced for drug trafficking seemed associated with a lower suicide risk. Drug trafficking (34.4\%) was the most frequent crime for those with and without a suicide risk in our study population and it is the only source of income for many. It might thus be more socially acceptable in parts of society and prison, and thus seen as a transient incident. But rape and sexual abuse are considered as major moral transgressions and are stigmatised in society and also in prison. There were no prisoners within those incarcerated for 


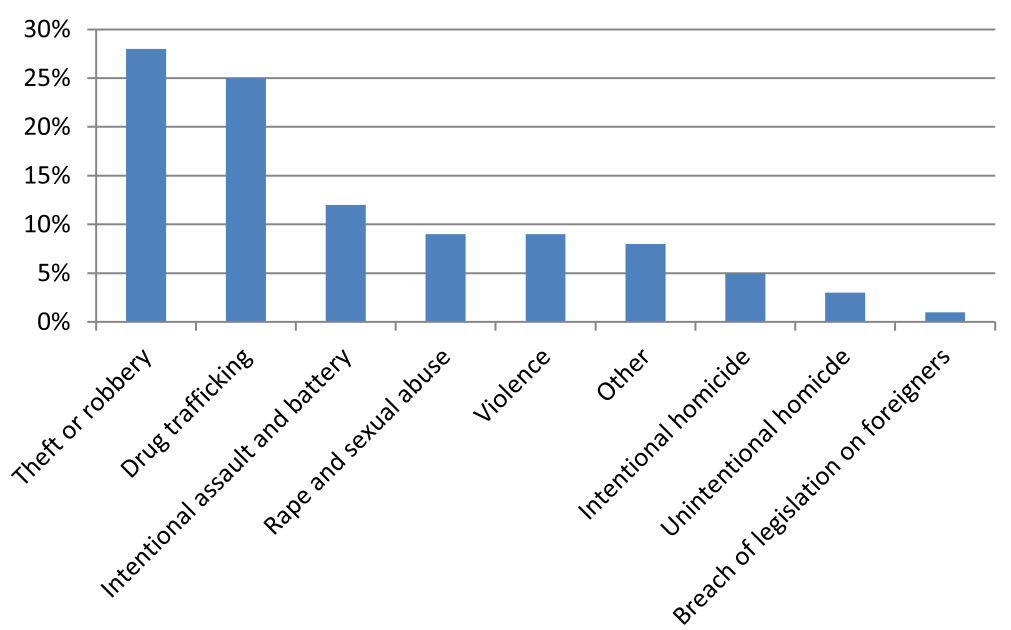

Fig. 1 Motives of incarceration of the inmates with a suicide risk in the French Guianese Prison, Cayenne, 2013/2014 $(n=707)$

rape or sexual assault who had been abused themselves. Being a victim of a sexual trauma or abuse during childhood was a highly significant risk factor, especially for men. Several studies showed the association of childhood abuse and suicidality, and conclude that targeting this population at risk should be a major prevention measure [39-41]. This phenomena has been confirmed by Ystgaard et al. when investigating repeated suicidal behaviour, but due to its complexity the entire mechanism is not yet fully understood [42]. In addition, the influence of childhood trauma on suicidal behaviour in inmates has been associated with the early onset of this behaviour, psychiatric disorder and destructive personality [43]. In an American study, childhood trauma was identified as an independent factor for female inmates but was not associated with substance abuse, mental disorders or incarceration duration [44]. This thus supports the hypothesis of an actual distress situation rather than a long-term condition. While smoking and substance abuse seemed to be associated with suicidal risk, alcohol consumption however was not. These variables have already been associated previously with suicide risk [7, 45]. Although young males have been reported to have a higher suicidal risk [37], we did not find a correlation between age and gender in our study population. For women (58\%) as for men $(38 \%)$ the majority of persons with a suicide risk were

Table 3 Comparison of prevalence of suicide risk of men in French Guiana between metropolitan France and Martinique

\begin{tabular}{llll}
\hline Suicide risk & $\mathrm{n}$ & $\%$ & $p$-value \\
\hline French Guiana, 2014 $(n=647)$ & 81 & 12.5 & \\
Metropolitan France, $2004(n=799)$ & 322 & 40.3 & $<0.0001^{* * *}$ \\
Martinique, 2004 $(n=100)$ & 26 & 26.0 & $<0.001^{* *}$ \\
\hline
\end{tabular}

${ }^{* *} p<0.01,{ }^{* * *} p<0.001$ indeed those between 20 and 30 years of age but these results were not statistically significant.

Characteristics, which we had intuitively predicted to affect suicidal risk, such as profession, early loss of relatives, family status, separation of parents in childhood, were not associated with suicidal risk in our study population. This multicultural population is often assumed to have very important differences. However, here there was no obvious difference between nationalities. What mattered was not culture but psychiatric disorders.

The study limitations were that it is declarative data in a context of incarceration which may have led a biased estimate. Some of the inmates refusing to answer may have had a different suicide risk than those who accepted. There have been debates about the necessity to formally validate suicide risk assessment tools [46]. The MINI scale has limitations failing to identify some cases of suicidality (false negatives). Although, a thorough evaluation of its validity would require further prospective studies, it has shown its interest in a prospective study [26].

The cross sectional design was also a limiting aspect since the risk varies in time after the initial incarceration shock. Despite these drawbacks, this was nevertheless a study using the same tools as the one conducted in France, which allowed to show the lower suicide risk in prison in French Guiana relative to France.

Table 4 Comparison of prevalence of suicide risk of women in French Guiana between metropolitan France and Martinique

Suicide risk

\begin{tabular}{llll}
\hline & $n$ & $\%$ & $p$-value \\
\hline French Guiana, 2014 $(n=60)$ & 12 & 20.0 & \\
Metropolitan France, 2004 $(n=99)$ & 61 & 61.0 & $<0.0001^{* * *}$
\end{tabular}

***p $<0.001$ 


\section{Conclusion}

This is the first study to measure the prevalence and the predictors of suicidal risk in the only French Guianese prison. To our knowledge, there are very few studies relative to suicidality in prison in South America or in the Caribbean. An initial assumption was that the multicultural South American context may have uncovered possibilities of risk stratification by nationality, a hypothesis that is refuted by the present results. Associations of suicide risk were found with mental disorders like depression, dysthymia, panic disorder and anxiety, males abused in childhood, smoking and being sentenced for sexual abuse. It gives a snapshot of the situation that will help improve the prevention of morbidity and mortality in prison, as required by French law since 2000. Longitudinal follow-up should further study time dependent aspects like the first incarceration shock and subsequent adaptation, and the influence of events within the prison such as other suicide attempts.

\section{Abbreviations}

Cl: Confidence Interval; DSI: Diagnostic Structured Interview; DSM-V: Diagnostic and Statistical Manual V; GAD: General Anxiety; INSERM: Institut national de la santé et de la recherche médicale; IRB: Institutional Review Board; MINI: Mini International Neuropsychiatric Interview; OR: Odds Ratio; UCSA: Unité de consultation et de soins ambulatoires; UFPI: Unité fonctionnelle de psychiatrie intra-carcérale; WHO: World Health Organisation

\section{Acknowledgements \\ Authors would like to acknowledge the correctional administration for permission, medical and paramedical staff for their collaboration, and the prisoners for participating in this study.}

\section{Funding}

No funding was obtained for this study.

\section{Availability of data and materials}

Generated or analysed data during this study are available from the corresponding author on reasonable request.

\section{Authors' contributions \\ GA contributed to design the study, organized the collection of data, analysed and interpreted the data and drafted the manuscript. RA contributed to design the study and critically revised the manuscript. CB supervised to design the study; quality assured feasibility of the study and revised the manuscript. VA contributed to collect data in the UCSA, supervised the work and critically revised the manuscript. AP contributed to collect data in the UCSA and critically revised the manuscript. EP and DS contributed to collect data in the UFPI. $L J$ and BF discussed the findings of the analyses and critically revised the manuscript. MN supervised the work, discussed the results and was involved in drafting and revising the manuscript. All authors have read and approved the latest version of the manuscript before it was admitted.}

\section{Competing interests}

The authors declare that they have no competing interests.

\section{Consent for publication}

Not applicable.

\section{Ethics approval and consent to participate}

We declare that this study was performed in line with the declaration of Helsinki and that ethical committee approval was obtained from the Comité d'évaluation Ethique de I'INSERM with IRB number IRB00003888. The correctional administration authorised the study and all persons gave informed consent.

\section{Publisher's Note}

Springer Nature remains neutral with regard to jurisdictional claims in published maps and institutional affiliations.

\section{Author details}

${ }^{1}$ Inserm CIC 1424, Centre d'Investigation Clinique Antilles Guyane, Centre Hospitalier de Cayenne, Avenue des Flamboyants, BP 6006, 97306 Cayenne CEDEX, France. ${ }^{2}$ Centre d'Investigation Clinique Antilles-Guyane, CIC INSERM 1424, Centre Hospitalier Andrée Rosemon, Cayenne, French Guiana, France. ${ }^{3}$ Unité de Soins et de Consultations Ambulatoires, Centre Hospitalier Andrée Rosemon, Cayenne, French Guiana, France. “Équipe IPSOM, INSERM 1178 , Paris, France. ${ }^{5}$ Department of Psychiatry, Centre Hospitalier Universitaire de Martinique, Fort-de-France, Martinique, France. ${ }^{6}$ EA3593, Université de Guyane, Cayenne, French Guiana, France.

Received: 11 February 2017 Accepted: 20 April 2017

Published online: 02 May 2017

\section{References}

1. Sher L. Preventing suicide. QJM - Mon J Assoc Physicians. 2004:97(10):677-80.

2. World Health Organization. Preventing Suicide in Jails and Prisons. 2007;1-24

3. Forrester A, Slade K. Preventing self-harm and suicide in prisoners: job half done. Lancet. 2014;383:1109-11.

4. Duburca A, Coulomb S, Bonte J, Marchand C, Fagnani F, Falissard B. Enquête de prévalence sur les troubles psychiatriques. Sommaire 2004; p. 17.

5. Fazel $S$, Benning R, Danesh J. Suicides in male prisoners in England and Wales, 1978-2003. Lancet. 2005;366(9493):1301-2.

6. Fazel S, Grann M, Kling B, Hawton K. Prison suicide in 12 countries: an ecological study of 861 suicides during 2003-2007. Soc Psychiatry Psychiatr Epidemiol. 2011;46(3):191-5.

7. Fazel S, Cartwright J, Norman-Nott A, Hawton K. Suicide in prisoners: a systematic review of risk factors. J Clin Psychiatry. 2008 Nov;69(11):1721-31.

8. Frühwald S, Matschnig T, Bauer P, Tier P. Suicide in custody: Case control study. Br J Psychiatry. 2004;185:494-8.

9. Jama-Alol KA, Malacova E, Ferrante A, Alan J, Stewart L, Preen D. Influence of offence type and prior imprisonment on risk of death following release from prison: a whole-population linked data study. Int J Prison Health. 2015;11(2):108-18.

10. Duthé G, Hazard A, Kensey A, Pan Ké Shon J. la France comparée à ses voisins européens. Popul Sociétés. 2009:462:2000-3.

11. Dye $\mathrm{MH}$. Deprivation, importation, and prison suicide: combined effects of institutional conditions and inmate composition. J Crim Justice. 2010;38(4): 796-806. Jul [cited 2016 Apr 11]. Available from: http://www.sciencedirect. com/science/article/pii/S0047235210001194

12. Ayirolimeethal A, Ragesh G, Ramanujam JM, George B. Psychiatric morbidity among prisoners. Indian J Psychiatry. 2014;56(2):150-3. [cited 2017 Jan 5]. Available from: https://www.ncbi.nlm.nih.gov/pmc/articles/PMC4040062/.

13. Saavedra J, López M. Risk of suicide in male prison inmates. Rev Psiquiatr y Salud Ment. 2015:8(4):224-31.

14. Rabe K. Prison structure, inmate mortality and suicide risk in Europe. Int J Law Psychiatry. 2012;35(3):222-30.

15. Chesneau P, Knibiehly M, Tichadou L, Calvez M, Joubert M, Hayek-Lanthois $M$, et al. Suicide attempt by ingestion of rotenone-containing plant extracts: one case report in French Guiana. Clin Toxicol (Phila). 2009:47(8):830-833. 5 [cited 2017 Jan 27]. Available from: http://www.tandfonline.com/doi/full/10. 1080/15563650903146818.

16. Sheehan D, Lecrubier $Y$, Harnett Sheehan K, Janavs J, Weiller E, Keskiner A, et al. The validity of the MINI International Neuropsychiatric interview (MINI) according to the SCID-P and its reliability. Eur Psychiatry. 1997; 12(5):232-41. [cited 2017 Jan 17]. Available from: http://linkinghub. elsevier.com/retrieve/pii/S092493389783297X

17. Lecrubier $Y$, Sheehan DV, Weiller E, Amorim P, Bonora I, Sheehan KH, et al. The MINI International Neuropsychiatric interview (MINI). A short diagnostic structured interview: reliability and validity according to the CIDI. Eur Psychiatry. 1997;12(5):224-31. Available from: http://dx.doi.org/10.1016/ S0924-9338(97)83296-8

18. Amorim $P$, Lecrubier $Y$, Weiller $E$, Hergueta $T$, Sheehan D. DSM-IH-R psychotic disorders: procedural validity of the MINI International Neuropsychiatric interview (MINI). Concordance and causes for discordance with the CIDI. Eur Psychiatry. 1998;13(1):26-34. Jan [cited 2017 Jan 17]. Available from: http://linkinghub.elsevier.com/retrieve/pii/ S092493389786748X 
19. Sheehan DV, Lecrubier $Y$, Sheehan KH, Amorim P, Janavs J, Weiller E, et al. The Mini-International Neuropsychiatric interview (M.I.N.I.): the development and validation of a structured diagnostic psychiatric interview for DSM-IV and ICD-10. J Clin Psychiatry. 1998;59(Suppl 20):22-33.

20. Sheehan D, Janavs J, Baker R, Harnett Sheehan K, Knapp E, Sheehan M, et al. M.I.N.I. Mini International Neuropsychiatric Interview. Vol. 5.0.0. 2006. p. 1-27.

21. de Azevedo Marques JM, Zuardi AW. Validity and applicability of the Mini International Neuropsychiatric interview administered by family medicine residents in primary health care in Brazil. Gen Hosp Psychiatry. 2008;30(4):303-10.

22. Black DW, Arndt S, Hale N, Rogerson R. Use of the MINI International Neuropsychiatric interview (MINI) as a screening tool in prisons: results of a preliminary study. J Am Acad Psychiatry Law. 2004;32:158-62.

23. Falissard B, Loze J-Y, Gasquet I, Duburc A, de Beaurepaire C, Fagnani F, et al. Prevalence of mental disorders in French prisons for men. BMC Psychiatry. 2006;6:33.

24. Maccio A, Meloni FR, Sisti D, Luigi Rocchi MB, Petretto DR, Masala C, et al. Mental disorders in Italian prisoners: results of the REDiMe study. Psychiatry Res. 2015; 225(3):522-30. Available from: http://dx.doi.org/10.1016/j.psychres.2014.11.053

25. Aboraya A. Use of Structured Interviews by Psychiatrists in Real Clinical Settings: Results of an Open-question Survey. Psychiatry (Edgmont) [Internet]. 2009;6(6):24-28. [cited 2017 Jan 26]. Available from: https://www. ncbi.nlm.nih.gov/pmc/articles/PMC2720839/.

26. Roaldset JO, Linaker OM, Bjørkly S. Predictive validity of the MINI suicidal scale for self-harm in acute psychiatry: a prospective study of the first year after discharge. Arch Suicide Res. 2012;16(4):287-302. Oct [cited 2017 Jan 26]. Available from: http://www.tandfonline.com/doi/abs/10.1080/13811118. 2013.722052

27. Duthé G, Hazard A, Kensey A. Suicide des personnes écrouées en France : évolution et facteurs de risque. Population (Paris). 2014;69(4):519. Available from: http://www.cairn.info/revue-population-2014-4-page-519.htm

28. Shaw J, Baker D, Hunt IM, Moloney A, Appleby L. Suicide by prisoners: national clinical survey. Br J Psychiatry. 2004;184(MAR):263-7.

29. Jaramillo Gutiérrez MR, Silva Vallejo C, Rojas Arango BP, Medina-Pérez ÓA. Ideación suicida y factores asociados en internos de un establecimiento penitenciario de Antioquia (Colombia). Rev Colomb Psiquiatr. 2015:44(2):100-5.

30. Fazel S, Danesh J. Serious mental disorder in 23000 prisoners: a systematic review of 62 surveys. Lancet. 2002;359(9306):545-50. 16 [cited 2016 Apr 11]. Available from: http://www.sciencedirect.com/science/article/pii/ S0140673602077401

31. Kilbane EJ, Gokbayrak NS, Galynker I, Cohen L, Tross S. A review of panic and suicide in bipolar disorder: does comorbidity increase risk? J Affect Disord. 2009;115(1-2):1-10. May [cited 2016 Apr 13]. Available from: http:// www.sciencedirect.com/science/article/pii/S0165032708003741

32. Frottier P, Fruhwald S, Ritter K, Eher R, Schwarzler J, Bauer P. Jailhouse blues revisited. Soc Psychiatry Psychiatr Epidemiol. 2002 Feb;37(2):68-73.

33. Way BB, Miraglia R, Sawyer DA, Beer R, Eddy J. Factors related to suicide in New York state prisons. Int J Law Psychiatry. 2005;28(3):207-21. Jan [cited 2016 Apr 11]. Available from: http://www.sciencedirect.com/science/article/ pii/S0160252705000427

34. Cox BJ, Direnfeld DM, Swinson RP, Norton GR. Suicidal Ideation and suicide attempts in panic disorder and social phobia. Am J Psychiatry. 1994;151(6): 82. Available from: http://dx.doi.org/10.1176/ajp.151.6.82

35. Lim S-W, Ko E-M, Shin D-W, Shin Y-C, Oh K-S. Clinical symptoms associated with suicidality in patients with panic disorder. Psychopathology. 2015;48(3):137-44.

36. Nam Y-Y, Kim C-H, Roh D. Comorbid panic disorder as an independent risk factor for suicide attempts in depressed outpatients. Compr Psychiatry. 2016;67:13-8. May [cited 2016 Apr 13]. Available from: http://www. sciencedirect.com/science/article/pii/S0010440X15301863.

37. Duthé G, Hazard A, Kensey A, JL S. Suicide among male prisoners in France: a prospective population-based study. Forensic Sci Int. 2013;233(1-3):273-7. 10 [cited 2016 Feb 5]. Available from: http://www.sciencedirect.com/ science/article/pii/S0379073813004313

38. DuRand CJ, Burtka GJ, Federman EJ, Haycox JA, Smith JW. A quarter century of suicide in a major urban jail: implications for community psychiatry. Am J Psychiatry. 1995;152(7):1077-80.

39. Hoertel N, Franco S, Wall MM, Oquendo MA, Wang S, Limosin F, et al. Childhood maltreatment and risk of suicide attempt. J Clin Psychiatry. 2015; 76(7):916-23. [cited 2017 Jan 26]. Available from: http://www.psychiatrist. com/jcp/article/Pages/2015/v76n07/v76n0720.aspx
40. Molnar BE, Berkman LF, Buka SL. Psychopathology, childhood sexual abuse and other childhood adversities: relative links to subsequent suicidal behaviour in the US. Psychol Med. 2001;31(6):965-77. [cited 2017 Jan 26]. Available from: https://www.cambridge.org/core/services/aop-cambridgecore/content/view/S0033291701004329

41. Eggertson L. Child sexual abuse in Nunavut linked to suicide. CMAJ. 2015; 187(16):E463-4. [cited 2017 Jan 26]. Available from: https://www.ncbi.nlm. nih.gov/pmc/articles/PMC4627888/

42. Ystgaard M, Hestetun I, Loeb M, Mehlum L. Is there a specific relationship between childhood sexual and physical abuse and repeated suicidal behavior? Child Abuse Negl. 2004;28(8):863-75.

43. Mandelli L, Carli V, Roy A, Serretti A, Sarchiapone M. The influence of childhood trauma on the onset and repetition of suicidal behavior: an investigation in a high risk sample of male prisoners. J Psychiatr Res. 2011; 45(6):742-7. Available from: http://dx.doi.org/10.1016/j.jpsychires.2010.11.005

44. Clements-Nolle K, Wolden M, Bargmann-Losche J. Childhood trauma and risk for past and Future suicide attempts among women in prison. Women's Heal Issues. 2009;19(3):185-92. Available from: http://dx.doi.org/10. 1016/j.whi.2009.02.002

45. Hawton K, van Heeringen K. Suicide. Lancet. 2009;373(9672):1372-81. 18 [cited 2016 Mar 25]. Available from: http://www.sciencedirect.com/science/ article/pii/S014067360960372X

46. Roos L, Sareen J, Bolton JM. Suicide risk assessment tools, predictive validity findings and utility today: time for a revamp? Neuropsychiatry (London). 2013;3(5):483-95. Available from: http://www.openaccessjournals.com/peerreview/from-objectivity-to-subjectivity-conceptualization-andmeasurementof-wellbeing-in-mental-health-neuropsychiatry.pdf

\section{Submit your next manuscript to BioMed Central and we will help you at every step:}

- We accept pre-submission inquiries

- Our selector tool helps you to find the most relevant journal

- We provide round the clock customer support

- Convenient online submission

- Thorough peer review

- Inclusion in PubMed and all major indexing services

- Maximum visibility for your research

Submit your manuscript at www.biomedcentral.com/submit
Ciomed Central 